\title{
Data-driven adaptive predictive control for an activated sludge process
}

\author{
Mashitah C. Razali ${ }^{1}$, Norhaliza Abdul Wahab ${ }^{2}$, Syahira Ibrahim ${ }^{3}$, Azavitra Zainal ${ }^{4}$, \\ M. F. Rahmat ${ }^{5}$, Ramon Vilanova ${ }^{6}$ \\ ${ }_{1,2,3,4,5}$ Control and Mechatronics Engineering, School of Electrical Engineering, \\ Universiti Teknologi Malaysia, Malaysia \\ ${ }^{6}$ Department de Telecomunicació i Enginyeria de Sistemes, Universitat Autònoma de Barcelona, Spain
}

\section{Article Info}

Article history:

Received Dec 1, 2019

Revised Mar 7, 2020

Accepted Apr 12, 2020

\section{Keywords:}

Data driven control

Direct adaptive

Subspace identification

\begin{abstract}
Data-driven control requires no information of the mathematical model of the controlled process. This paper proposes the direct identification of controller parameters of activated sludge process. This class of data-driven control calculates the predictive controller parameters directly using subspace identification technique. By updating input-output data using receding window mechanism, the adaptive strategy can be achieved. The robustness test and stability analysis of direct adaptive model predictive control are discussed to realize the effectiveness of this adaptive control scheme. The applicability of the controller algorithm to adapt into varying kinetic parameters and operating conditions is evaluated. Simulation results show that by a proper and effective excitation of direct identification of controller parameters, the convergence and stability of the implicit predictive model can be achieved.
\end{abstract}

This is an open access article under the CC BY-SA license.

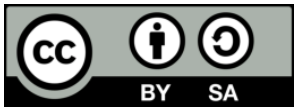

\section{Corresponding Author:}

Norhaliza Abdul Wahab,

Control and Mechatronics Engineering,

School of Electrical Engineering,

Universiti Teknologi Malaysia,

81310 Skudai Johor Bahru, Malaysia.

Email: aliza@fke.utm.my

\section{INTRODUCTION}

In the biological activated sludge process (ASP), microbial contaminants are used in influent wastewater to degrade organic matters and nutrients [1-3]. Due to the system's dynamic uncertainties and highly nonlinearities in the microorganism's growth kinetic model, control of activated sludge process is a challenge. Conventional controllers are designed based on mathematical model of ASP which requires the designer to spend lot of building the model from the basic laws of biomass mass balance. However, there are model free design methods available that can be utilized in designing control systems [4-6]. For conventional control, the differential equations derived are then transformed into a standard transfer function or state space and the control laws are then applied [7-10]. However, the principal control problems of ASP as found in literature can be briefly illustrated by the variability of the kinetic parameter [11-12], time-varying influent conditions, nonlinearities [13], delays, lack of accurate sensors [14], and the limited availability of the online measurements [15]. Therefore, adaptive control principles are the preferred design option [16-18].

The main issue in the design of predictive controller for ASP was how to implement an accurate internal predictive model which best describes the behavior of the biochemical process involved. In [19] the internal predictive model of the plant implemented neural networks for controller design. However, this method suffers from the fact that it requires much attention on the training data collection 
resulting in many approximations in this stage of the design, and huge validation experiments have to be done to accurately identify the model and it's usually fails to track the variability of the kinetic parameters. In [20] the authors have built the internal model for prediction based on linearized state space model of the bioprocess which is definitely undesirable in cases of variability in the effluents or any changes in operating conditions. Subspace Identification techniques developed in nineties offers an attractive and effective solution for the issue of prediction model and has been deployed successfully in design of predictive controllers for multiple-input multiple-output processes [21].

The employment of the robust computational tools such as QR-decomposition has recently opened a wide area of research to develop a single step implementation for predictive controllers where only input-output data are processed to directly calculate controller parameters or namely "Model-free" control methods [22]. The results of [22-24] are some of the successful reports for this class of novel algorithms. However, they have not introduced any closed-loop stability analysis for the sake of practical implementation of the proposed controller. Most adaptive predictive controllers reported so far are only applied to linear systems or indirectly implemented. Therefore, the stability involved can be easily examined and proved for several cases of infinite prediction horizon or when the open loop system can be accessed and is stable. However, when the system is nonlinear or when finite horizons is applied, only few approaches have been published and were limited to indirect schemes [25-26]. In this paper, a data-driven predictive controller for activated sludge process is applied which is also consider stability of the proposed controller.

\section{ACTIVATED SLUDGE MODEL DEVELOPMENT}

The biological process is modeled from component-balance considerations and the obtained model is most often a highly complex and high-order non-linear system given by the following set of nonlinear differential equations [27]:

$$
\begin{aligned}
& \frac{d X(t)}{d t}=\mu(t) X(t)-D(t)(1+r) X(t)+r D(t) X_{r}(t) \\
& \frac{d S(t)}{d t}=-\frac{\mu(t)}{Y} X(t)-D(t)(1+r) S(t)+D(t) S_{i n} \\
& \frac{d C(t)}{d t}=-\frac{K_{0} \mu(t)}{Y} X(t)-D(t)(1+r) C(t)+K_{L a}\left(C_{s}-C(t)\right)+D(t) C_{i n} \\
& \frac{d X_{r}(t)}{d t}=D(t)(1+r) X(t)-D(t)(\beta+r) X_{r}(t)
\end{aligned}
$$

where $\mathrm{X}(\mathrm{t}), \mathrm{S}(\mathrm{t}), \mathrm{X}_{\mathrm{r}}(\mathrm{t}), \mathrm{C}(\mathrm{t})$ are the state variables representing the biomass, the substrate, the recycled biomass and dissolved oxygen concentrations, respectively. Meanwhile, $\mathrm{D}(\mathrm{t})$ is the dilution rate, and $\mathrm{r}$ and $\beta$ represent the ratio of recycled flow to influent flow and ratio of waste flow to influent flow, $S_{\text {in }}$ and $C_{\text {in }}$ respectively, which corresponds to the substrate and dissolved oxygen concentrations in the influent stream. In addition, $\mathrm{Y}$ is the cell mass; $\mathrm{K}_{0}$ is a constant term, $\mathrm{C}_{\mathrm{s}}$ is the maximum dissolved oxygen concentration and $\mathrm{K}_{\mathrm{La}}$ represents the oxygen mass transfer coefficient.

$$
\mathrm{K}_{\mathrm{La}}=\alpha \mathrm{W}, \alpha>0
$$

where $\mathrm{W}$ is the airflow rate. The kinetic model of the specific cell mass production rate $\mu(\mathrm{t})$ is given as [24].

$$
\mu(t)=\mu_{\max } \frac{\mathrm{S}(\mathrm{t})}{\mathrm{K}_{\mathrm{s}}+\mathrm{S}(\mathrm{t})} \frac{\mathrm{C}(\mathrm{t})}{\mathrm{K}_{\mathrm{c}}+\mathrm{C}(\mathrm{t})}
$$

where $\mu_{\max }$ is the maximum specific growth rate, $\mathrm{K}_{\mathrm{s}}$ is the so-called affinity constant, expressing the dependency of the degradation rate on the concentration of pollutant $S$, and $\mathrm{K}_{\mathrm{c}}$ is the saturation constant. Notice that all the above equations are only used here in this work to generate input-output (I/O) data and they will not be used in any stage of the controller design. For simulations purpose, the process parameters, kinetic parameters, and initial conditions are adopted, as shown in Tables 1-3, respectively.

Table 1. Process parameters

\begin{tabular}{ll}
\hline Parameter & Value \\
\hline$\Upsilon$ & 0.65 \\
$\mathrm{r}$ & 0.6 \\
$\beta$ & 0.2 \\
$\alpha$ & $0.018 \mathrm{~m}^{-3}$ \\
$\mathrm{~K}_{0}$ & 0.5 \\
$\mathrm{C}_{\mathrm{s}}$ & $10 \mathrm{mgl}^{-1}$ \\
$\mathrm{~S}_{\text {in }}$ & $200 \mathrm{mgl}^{-1}$ \\
$\mathrm{C}_{\text {in }}$ & $0.5 \mathrm{mgl}^{-1}$ \\
\hline
\end{tabular}

Table 2. Kinetic parameters

\begin{tabular}{ll}
\hline Parameter & Value \\
\hline $\mathrm{r}$ & 0.65 \\
$\mathrm{r}$ & 0.6 \\
$\beta$ & 0.2 \\
$\alpha$ & $0.018 \mathrm{~m}^{-3}$ \\
$\mathrm{~K}_{0}$ & 0.5 \\
$\mathrm{C}_{\mathrm{s}}$ & $10 \mathrm{mgl}^{-1}$ \\
$\mathrm{~S}_{\text {in }}$ & $200 \mathrm{mgl}^{-1}$ \\
$\mathrm{C}_{\text {in }}$ & $0.5 \mathrm{mgl}^{-1}$ \\
\hline
\end{tabular}

Table 3. Initial conditions

\begin{tabular}{ll}
\hline Parameter & Value \\
\hline $\mathrm{X}(0)$ & $215 \mathrm{mgl}^{-1}$ \\
$\mathrm{~S}(0)$ & $35 \mathrm{mgl}^{-1}$ \\
$\mathrm{C}(0)$ & $6 \mathrm{mgl}^{-1}$ \\
$\mathrm{X}_{\Upsilon}(0)$ & $400 \mathrm{mgl}^{-1}$ \\
$\mathrm{~S}_{\text {in }}$ & $200 \mathrm{mgl}^{-1}$ \\
$\mathrm{C}_{\text {in }}$ & $0.5 \mathrm{mgl}^{-1}$ \\
\hline
\end{tabular}




\section{SUBSPACE BASED PREDICTOR IDENTIFICATION}

The most commonly used technique in system identification is used in this paper, given by (7):

$$
x_{t+1}=A x_{t}+B u_{t}+K e_{t} \text { and } y_{t}=C x_{t}+D u_{t}+e_{t}
$$

where, $x_{t} \in \mathbb{R}^{n}$, is the system states with order $n, u_{t} \in \mathbb{R}^{N_{u}}$, is the input vector with $N_{u}$ number of inputs, $y_{t} \in \mathbb{R}^{N_{y}}$ is the output vector with $N_{y}$ number of outputs and, $e_{k}$ is a white noise disturbance (innovations) sequence with covariance $\Sigma_{\mathrm{e}}$. The matrices $A \in \mathbb{R}^{\mathrm{n} \times \mathrm{n}}, \mathrm{B} \in \mathbb{R}^{\mathrm{n} \times \mathrm{N}_{\mathrm{u}}}, \mathrm{C} \in \mathbb{R}^{\mathrm{n} \times \mathrm{N}_{\mathrm{y}}}, \mathrm{D} \in \mathbb{R}^{\mathrm{N}_{\mathrm{u}} \times \mathrm{N}_{\mathrm{y}}}$ and $\mathrm{K} \in \mathbb{R}^{\mathrm{N}_{\mathrm{y}} \times \mathrm{N}_{\mathrm{y}}}$ are the state, input, output, feed-forward and Kalman gain matrices of the system. The following (8) to (10) are defined as fundamental subspace I/O matrix equations. The subscripts $p$ here denotes "past" and $f$ denotes "future" matrices for its respective variables.

$$
\begin{aligned}
& Y_{p}=\Gamma_{i} X_{p}+H_{i}^{d} U_{p}+H_{i}^{s} E_{p} \\
& Y_{f}=\Gamma_{i} X_{f}+H_{i}^{d} U_{f}+H_{i}^{s} E_{f} \\
& X_{f}=A^{i} X_{p}+\Delta_{i}^{d} U_{p}+\Delta_{i}^{s} E_{p}
\end{aligned}
$$

where the extended observability matrix $\Gamma_{i}$, the reversed extended controllability matrix for deterministic input $\Delta_{\mathrm{i}}^{\mathrm{d}}$ and for stochastic input $\Delta_{\mathrm{i}}^{\mathrm{s}}$, matrices $\mathrm{H}_{\mathrm{i}}^{\mathrm{d}}$ and $\mathrm{H}_{\mathrm{i}}^{\mathrm{s}}$ are the lower triangular Toeplitz matrices for both deterministic and stochastic parts, respectively. Assuming that the open-loop I/O data $u_{k}$ and $y_{k}$ for $\mathrm{k}=\{0,1, \ldots, \mathrm{N}-1\}$ are available for the identification, define the past input, $\mathrm{U}_{\mathrm{p}}$ and future input, $\mathrm{U}_{\mathrm{f}}$ data matrices for (8)-(10) as follows:

$$
\begin{gathered}
\mathrm{U}_{\mathrm{p}} \triangleq \mathrm{U}_{\langle 0 \mid \mathrm{i}-1\rangle} \triangleq\left[\begin{array}{cccc}
\mathrm{u}_{0} & \mathrm{u}_{1} & \cdots & \mathrm{u}_{\mathrm{N}-2 \mathrm{i}} \\
\mathrm{u}_{1} & \mathrm{u}_{2} & \cdots & \mathrm{u}_{\mathrm{N}-2 \mathrm{i}+1} \\
\cdots & \cdots & \ddots & \cdots \\
\mathrm{u}_{\mathrm{i}-1} & \mathrm{u}_{\mathrm{i}} & \cdots & \mathrm{u}_{\mathrm{N}-\mathrm{i}}
\end{array}\right] \\
\mathrm{U}_{\mathrm{f}} \triangleq \mathrm{U}_{\langle\mathrm{i} \mid 2 \mathrm{i}-1\rangle} \triangleq\left[\begin{array}{cccc}
\mathrm{u}_{\mathrm{i}} & \mathrm{u}_{\mathrm{i}+1} & \cdots & \mathrm{u}_{\mathrm{N}-\mathrm{i}} \\
\mathrm{u}_{\mathrm{i}+1} & \mathrm{u}_{\mathrm{i}+2} & \cdots & \mathrm{u}_{\mathrm{N}-\mathrm{i}+1} \\
\cdots & \cdots & \ddots & \cdots \\
\mathrm{u}_{2 \mathrm{i}-1} & \mathrm{u}_{2 \mathrm{i}} & \cdots & \mathrm{u}_{\mathrm{N}-1}
\end{array}\right]
\end{gathered}
$$

where $\left\{U_{p}, U_{f}\right\} \in \mathbb{R}^{N_{u} i \times N-2 i}$. The subscripts $\left\langle k_{1} \mid k_{2}\right\rangle$ indicates that the first column of the subspace matrix starts from the time step $k_{1}$ and ends by the time step $k_{2}$. Similar notation can be written for past and future output matrices. In subspace identification literature, the following short-hand notation is commonly used:

$$
\begin{aligned}
& W_{p}=\left[\begin{array}{c}
Y_{p} \\
U_{p}
\end{array}\right] \\
& Y_{f}=L_{w} W_{p}+L_{u} U_{f}
\end{aligned}
$$

Equation (14) is the subspace predictor equation where the parameters to be obtained contain system model information without completely identifying the parametric model of the system such as the conventional transfer function or state space representation of the system. In addition, $L_{w} \mathbb{R}^{i N_{y} \times i\left(N_{y}+N_{u}\right)}$ : is the subspace matrix that corresponds to the past inputs and outputs. $\mathrm{L}_{\mathrm{u}} \mathbb{R}^{\mathrm{iN} \mathrm{N}_{\mathrm{y}} \times \mathrm{iN}_{\mathrm{u}}}$ : is the subspace matrix that corresponds to the future input data or the deterministic inputs, and $\mathrm{L}_{\mathrm{u}}=\mathrm{H}_{\mathrm{i}}^{\mathrm{d}}$. The problem of obtaining the best linear predictor of the future outputs $\widehat{Y}_{f}$, given the past inputs and outputs in the form of $W_{p}$ and the future inputs $U_{f}$ can be written as a Frobenius norm minimization:

$$
\min _{\mathrm{L}_{\mathrm{w}}, \mathrm{L}_{\mathrm{u}}}\left\|\mathrm{Y}_{\mathrm{f}}-\left[\begin{array}{ll}
\mathrm{L}_{\mathrm{w}} & \mathrm{L}_{\mathrm{u}}
\end{array}\right]\left[\begin{array}{c}
\mathrm{W}_{\mathrm{p}} \\
\mathrm{U}_{\mathrm{f}}
\end{array}\right]\right\|_{\mathrm{F}}^{2}
$$

The least square problem in (15) can be solved by the orthogonal projection and can be implemented by forming a QR-decomposition of the matrix $\left[\begin{array}{lll}W_{p}^{T} & U_{f}^{T} & Y_{f}^{T}\end{array}\right]^{T}$ as follows: 


$$
\left[\begin{array}{c}
W_{p} \\
U_{f} \\
Y_{f}
\end{array}\right]=\left[\begin{array}{ccc}
R_{11} & 0 & 0 \\
R_{21} & R_{22} & 0 \\
R_{31} & R_{32} & R_{33}
\end{array}\right]\left[\begin{array}{l}
Q_{1} \\
Q_{2} \\
Q_{3}
\end{array}\right]
$$

Thus, we can estimate optimal prediction $\widehat{Y}_{f}$ as described in (16). $L_{w}$, and $L_{u}$ can be used to formulate an estimation of future outputs as follows:

$$
\left[\begin{array}{c}
\hat{y}_{k} \\
\vdots \\
\hat{y}_{k+i-1}
\end{array}\right]=L_{w}\left[\begin{array}{c}
u_{k-i} \\
\vdots \\
u_{k-1} \\
y_{k-i} \\
\vdots \\
y_{k-1}
\end{array}\right]+L_{u}\left[\begin{array}{c}
u_{k} \\
\vdots \\
u_{k-i-1}
\end{array}\right]
$$

Equation (17) is a streamlined subspace-based linear predictor equation which can be written as,

$$
\hat{y}_{f}=L_{w} w_{p}+L_{u} u_{f}
$$

\section{DIRECT ADAPTIVE MODEL PREDICTIVE CONTROL}

In the direct adaptive model predictive control (DAMPC) or so-called data driven method, the controller parameters are estimated directly from the measurements. Therefore, the system model is implicitly included and no explicit model is formulated at any stage of the implementation. The adaptive mechanism implemented here adjusts the predictive controller parameters to the changes in the process dynamics in every sampling time. The measured input-output data is collected over a sliding window. It can be noted that the data window used to identify the controller parameters or state matrices can be expressed in terms of future inputs, $\mathrm{u}_{\mathrm{f}}=\left[\begin{array}{llll}\mathrm{u}_{\mathrm{i}-1} & \cdots & \mathrm{u}_{2 \mathrm{i}-2}\end{array}\right]^{\mathrm{T}}$ and measurement (past) inputs $\mathrm{u}_{\mathrm{p}}=\left[\begin{array}{llll}\mathrm{u}_{0} & \cdots & \mathrm{u}_{\mathrm{i}-1}\end{array}\right]^{\mathrm{T}}$ and outputs $\mathrm{y}_{\mathrm{p}}=\left[\begin{array}{lll}\mathrm{y}_{0} & \cdots & \mathrm{y}_{\mathrm{i}-1}\end{array}\right]^{\mathrm{T}}$. Here, two prediction problems are given at current time instant $\mathrm{i}$ and $\mathrm{i}+1$ as shown in Figure 2. The first prediction problem $(\mathrm{t}=\mathrm{i})$ represents the case for obtaining the optimal prediction of $i$ future outputs $\hat{y}_{f}=\left[\begin{array}{llll}\hat{y}_{i} & \cdots & \hat{y}_{i-2 i-1}\end{array}\right]^{T}$ using the information given in the previously stated data window $\mathrm{u}_{\mathrm{p}}, \mathrm{y}_{\mathrm{p}}$ and $\mathrm{u}_{\mathrm{f}}$. The second prediction problem shows that the time instant slides from $t=i$ to $t=i+1$, this differs from the data window $\left(u_{p}, y_{p}\right.$ and $\left.u_{f}\right)$ which is now slides from left to right. At every time step, for the new available input-output data, the MPC parameters are updated online according to the updated predictor gain matrices and a new control action is computed. The cost function performance criterion used can be written in matrix form as,

$$
J=\left(\hat{y}_{f}-r_{f}\right)^{T} Q\left(\hat{y}_{f}-r_{f}\right)+\Delta u_{H_{c}}^{T} R \Delta u_{H_{c}}
$$

where, $r_{\mathrm{f}}=\left[\begin{array}{c}\mathrm{I}_{\mathrm{N}_{\mathrm{y}}} \\ \mathrm{I}_{\mathrm{N}_{\mathrm{y}}} \\ \vdots \\ \mathrm{I}_{\mathrm{N}_{\mathrm{y}}}\end{array}\right] \mathrm{r}_{\mathrm{t}+1}, \Delta \mathrm{u}_{\mathrm{H}_{\mathrm{c}}}=\left[\begin{array}{c}\Delta \mathrm{u}_{\mathrm{t}+1} \\ \Delta \mathrm{u}_{\mathrm{t}+2} \\ \vdots \\ \Delta \mathrm{u}_{\mathrm{t}+\mathrm{H}_{\mathrm{c}}}\end{array}\right]$. By incorporating the integral action to the subspace predictive model, (20) is derived:

$$
\hat{y}_{\mathrm{f}}=\mathrm{F}_{\mathrm{N}_{\mathrm{y}}} \mathrm{y}_{\mathrm{t}}+\mathcal{F}_{\mathrm{N}_{\mathrm{y}}} \mathrm{L}_{\mathrm{w}} \Delta \mathrm{w}_{\mathrm{p}}+\mathcal{F}_{\mathrm{N}_{\mathrm{y}}} \mathrm{L}_{\mathrm{u}}^{\mathrm{H}_{\mathrm{c}}} \Delta \mathrm{u}_{\mathrm{H}_{\mathrm{c}}}
$$

where, $\mathcal{F}_{\mathrm{N}_{\mathrm{y}}}=\left[\begin{array}{ccc}\mathrm{I}_{\mathrm{N}_{\mathrm{y}}} & \cdots & 0 \\ \vdots & \ddots & \vdots \\ \mathrm{I}_{\mathrm{N}_{\mathrm{y}}} & \cdots & \mathrm{I}_{\mathrm{N}_{\mathrm{y}}}\end{array}\right]$ and $\mathrm{L}_{\mathrm{u}}^{\mathrm{H}_{\mathrm{c}}}=\mathrm{L}_{\mathrm{u}}\left[\begin{array}{c}\mathrm{I}_{\mathrm{H}_{\mathrm{c}} \mathrm{N}_{\mathrm{u}}} \\ 0_{\mathrm{N}_{\mathrm{u}} \times \mathrm{H}_{\mathrm{c}}}\end{array}\right]$. Then, we can rewrite (19) as:

$$
\mathrm{J}=\frac{1}{2} \Delta \mathrm{u}_{\mathrm{H}_{\mathrm{c}}}^{\mathrm{T}} \Omega \Delta \mathrm{u}_{\mathrm{H}_{\mathrm{c}}}+\Delta \mathrm{u}_{\mathrm{H}_{\mathrm{c}}}^{\mathrm{T}} \Xi
$$

with, $\Omega=\left(\mathcal{F}_{\mathrm{N}_{\mathrm{y}}} \mathrm{L}_{\mathrm{u}}^{\mathrm{H}_{\mathrm{c}}}\right)^{\mathrm{T}} \mathrm{Q}\left(\mathcal{F}_{\mathrm{N}_{\mathrm{y}}} \mathrm{L}_{\mathrm{u}}^{\mathrm{H}_{\mathrm{c}}}\right)+\mathrm{R}$ and $\Xi=\left(\mathcal{F}_{\mathrm{N}_{\mathrm{y}}} \mathrm{L}_{\mathrm{u}}^{\mathrm{H}_{\mathrm{c}}}\right)^{\mathrm{T}} \mathrm{Q}\left(\mathcal{F}_{\mathrm{N}_{\mathrm{y}}} \mathrm{L}_{\mathrm{w}} \Delta \mathrm{w}_{\mathrm{p}}+\mathrm{F}_{\mathrm{N}_{\mathrm{y}}}\left(\mathrm{y}_{\mathrm{t}}-\mathrm{r}_{\mathrm{t}+1}\right)\right)$. In this case, the model predictive law for the unconstrained case of the problem of (21) is derived, which can be simply solved by: 


$$
\begin{aligned}
& \frac{\delta \mathrm{J}}{\delta \Delta \mathrm{u}_{\mathrm{H}_{\mathrm{c}}}}=\Omega \Delta \mathrm{u}_{\mathrm{H}_{\mathrm{c}}}+\Xi=0 \\
& \Delta \mathrm{u}_{\mathrm{H}_{\mathrm{c}}}=-\Omega^{-1} \Xi
\end{aligned}
$$

At time t, only $\Delta \mathrm{u}(1)$ is implemented and the calculation is repeated at each time instant. Hence, the control law is as follows:

$$
\Delta \mathrm{u}(1)=-\mathrm{K}_{\Delta \mathrm{w}_{\mathrm{p}}} \Delta \mathrm{w}_{\mathrm{p}}-\mathrm{K}_{\mathrm{e}}\left(\mathrm{y}_{\mathrm{t}}-\mathrm{r}_{\mathrm{t}+1}\right)
$$

with, $\mathrm{K}_{\Delta \mathrm{w}_{\mathrm{p}}}=\left[\begin{array}{ll}\mathrm{I}_{\mathrm{N}_{\mathrm{u}}} & 0_{\mathrm{N}_{\mathrm{u}} \times\left(\mathrm{H}_{\mathrm{c}}-1\right) \mathrm{N}_{\mathrm{u}}}\end{array}\right] \mathrm{K}_{\Delta \mathrm{w}_{\mathrm{p}}, \mathrm{H}_{\mathrm{c}}}$ and $\mathrm{K}_{\mathrm{e}}=\left[\begin{array}{ll}\mathrm{I}_{\mathrm{N}_{\mathrm{u}}} & 0_{\mathrm{N}_{\mathrm{u}} \times\left(\mathrm{H}_{\mathrm{c}}-1\right) \mathrm{N}_{\mathrm{u}}}\end{array}\right] \mathrm{K}_{\mathrm{e}, \mathrm{H}_{\mathrm{c}}}$. Where $\mathrm{K}_{\Delta \mathrm{w}_{\mathrm{p}}, \mathrm{H}_{\mathrm{c}}}$ and $\mathrm{K}_{\mathrm{e}, \mathrm{H}_{\mathrm{c}}}$ defined as,

$$
\begin{aligned}
& \mathrm{K}_{\Delta \mathrm{w}_{\mathrm{p}}, \mathrm{H}_{\mathrm{c}}}=\left(\left(\mathcal{F}_{\mathrm{N}_{\mathrm{y}}} \mathrm{L}_{\mathrm{u}}^{\mathrm{H}_{\mathrm{c}}}\right)^{\mathrm{T}} \mathrm{Q}\left(\mathcal{F}_{\mathrm{N}_{\mathrm{y}}} \mathrm{L}_{\mathrm{u}}^{\mathrm{H}_{\mathrm{c}}}\right)+\mathrm{R}\right)^{-1}\left(\mathcal{F}_{\mathrm{N}_{\mathrm{y}}} \mathrm{L}_{\mathrm{u}}^{\mathrm{H}_{\mathrm{c}}}\right)^{\mathrm{T}} \mathrm{Q}\left(\mathcal{F}_{\mathrm{N}_{\mathrm{y}}} \mathrm{L}_{\mathrm{w}}\right) \\
& \mathrm{K}_{\mathrm{e}, \mathrm{H}_{\mathrm{c}}}=\left(\left(\mathcal{F}_{\mathrm{N}_{\mathrm{y}}} \mathrm{L}_{\mathrm{u}}^{\mathrm{H}_{\mathrm{c}}}\right)^{\mathrm{T}} \mathrm{Q}\left(\mathcal{F}_{\mathrm{N}_{\mathrm{y}}} \mathrm{L}_{\mathrm{u}}^{\mathrm{H}_{\mathrm{c}}}\right)+\mathrm{R}\right)^{-1}\left(\mathcal{F}_{\mathrm{N}_{\mathrm{y}}} \mathrm{L}_{\mathrm{u}}^{\mathrm{H}_{\mathrm{c}}}\right)^{\mathrm{T}} \mathrm{Q} \mathrm{F}_{\mathrm{N}_{\mathrm{y}}}
\end{aligned}
$$

\section{SIMULATION AND RESULTS}

The implemented control system is a two inputs two outputs system that are dilution rate, D and air flow rate, $\mathrm{W}$ for the inputs, and substrate, $\mathrm{S}$ and dissolved oxygen, $\mathrm{C}$ for the outputs. The simulation is run from a steady state operating point at outputs $S=41.23 \mathrm{mg} / \mathrm{l}, \mathrm{C}=6.11 \mathrm{mg} / \mathrm{l}$ and inputs $\mathrm{D}=0.081 / \mathrm{hr}$ and $\mathrm{W}=90$ $\mathrm{m} 3 / \mathrm{hr}$. The sampling period is chosen as $\mathrm{Ts}=1$. The weighting matrices are chosen as $\mathrm{Q}=\operatorname{diag}(1,10)$ and $\mathrm{R}=\operatorname{diag}\left(10^{4}, 10^{-4}\right)$. Meanwhile, the Prediction Horizon, $\mathrm{H}_{\mathrm{p}}$ and Control Horizon, $\mathrm{H}_{\mathrm{c}}$ were 35 , and 5 respectively. Figure 1 shows the evolution of the outputs and inputs. The setpoint given for the outputs are varied for an approximately $10 \%$ around the system's steady state condition. The squared error performance index was chosen to evaluate the performance of the closed-loop system and it was found to be 445.2.
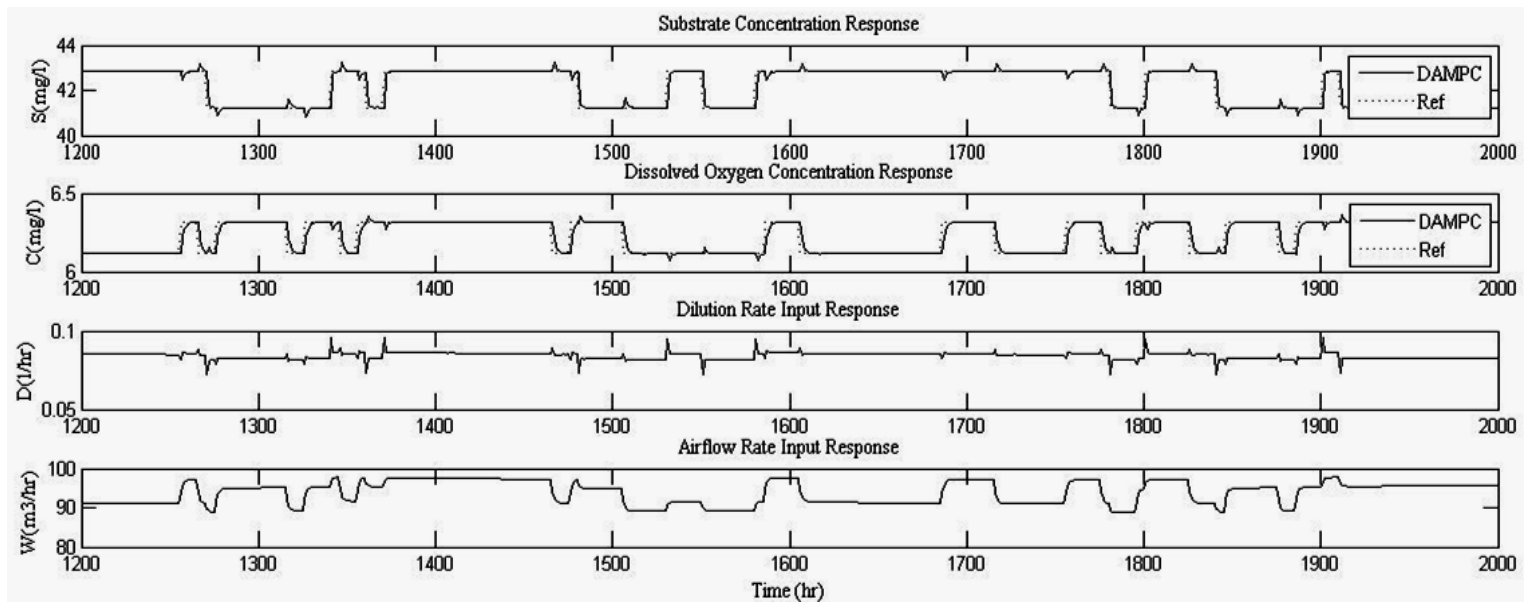

Figure 1. Closed-loop response of substrate, dissolved oxygen, dilution rate and airflow rate

\subsection{Stability analysis of subspace based DAMPC}

In this section, the stability of the DAMPC is investigated. The design methodology is based on receding horizon control, which is also used in a standard model predictive control (MPC) system design. However, the main differentiating part between the DAMPC and a commonly used MPC is the starting point in the design. The starting point for the usual design of MPC is the availability of a dynamic model that describes the system to be controlled. With given sufficient accuracy of the model, long prediction horizon and control horizon, the closed-loop stability of MPC is obtained. In contrast, the starting point for the design of subspace-based DAMPC is the availability of excitation test data for the system to be controlled. Here, the question on the closed-loop stability of DAMPC is associated with the excitation test data for the system, as well as the prediction horizon and control horizon. 
Several simulations of DAMPC showed that large prediction horizons may also resulted in larger errors of predictions since the actual system is nonlinear and the prediction based on subspace matrices is linear. Also, the longer the prediction horizon, of the DAMPC would approach as the classical MPC. The focus of the investigation on stability of the closed-loop system was on the quantity and quality of the excitation test data. Particularly, simulation studies are carried out to investigate the effect of both the window size of data length and prediction horizon length and the closed-loop performance criterion for various numerical values are shown. The best results obtained were $n=400$ and $H_{p}=35$ for both window size length and prediction horizon, respectively. The relationship of closed-loop stability to the predictor estimation algorithm is proposed. It can be seen, if the prediction converges to the true value, the overall closed-loop system will be equivalent to the standard MPC. From the convergence analysis of this algorithm, if a long enough prediction horizon for estimation is used, then the multi-step ahead estimated predictions will converge to the true multi-step ahead predictions. This can be proven by looking through the linear equation used to calculate the estimated output prediction presented again as:

$$
\hat{y}_{f}=L_{w} w_{p}+L_{u} u_{f} \triangleq y_{f}^{p}+\hat{y}_{f}^{f}
$$

where: $y_{\mathrm{f}}^{\mathrm{p}}$ : The natural response, or the effect of the initial conditions is considered to be deterministic since it resulted from the multiplication by the past inputs and outputs $\mathrm{w}_{\mathrm{p}}$.

$\hat{y}_{\mathrm{f}}^{\mathrm{f}}$ : The forced response which is clearly resulted from the effect of the input over the prediction horizon which is in fact the impulse response coefficients due to the future input increments.

$$
\begin{aligned}
& y_{f}^{p}=\left[\begin{array}{c}
C \\
C A \\
\vdots \\
C A^{i-1}
\end{array}\right] x_{k} \Rightarrow y_{k}^{p}=C A^{i-1} x_{k-i+1} \triangleq L_{w} w_{p} \\
& \hat{y}_{f}^{f}=\left[\begin{array}{ccccc}
D & 0 & & \cdots & 0 \\
C B & D & & \cdots & 0 \\
\cdots & \cdots & \ddots & & \cdots \\
C A^{i-2} B & C A^{i-3} B & & \cdots & D
\end{array}\right]\left[\begin{array}{c}
u_{k} \\
u_{k+1} \\
\vdots \\
u_{k+i-1}
\end{array}\right] \\
& \Rightarrow \hat{y}_{\mathrm{k}}^{\mathrm{f}}=\mathrm{Du}_{\mathrm{k}}+\sum_{\mathrm{n}=1}^{\mathrm{i}-1} \mathrm{CA}^{\mathrm{n}-1} \mathrm{Bu}_{\mathrm{k}-\mathrm{n}} \triangleq \mathrm{L}_{\mathrm{u}} \mathrm{u}_{\mathrm{f}}
\end{aligned}
$$

Due to the nature of this algorithm, it will converge globally, which an important property with respects to the typical adaptive algorithms is found in the literature. Here we can conclude that if the future inputs remain bounded we can assure the convergence and the stability of the implicit predictive model which can only be proven by investigating the values of the impulse coefficients incorporated into prediction gain matrices over the prediction horizon. Therefore, by plotting $\mathrm{L}_{\mathrm{u}}$ for every manipulated variable, the convergence of the predictive model to the true value over the prediction horizon can be illustrated. Figure 2 shows the values of $\mathrm{L}_{\mathrm{u}}$ for both the future dilution rate manipulated variable and airflow rate manipulated variable is bounded over the prediction horizon. Therefore, it ensures the convergence of $t$ he estimated output prediction to the true value accordingly.

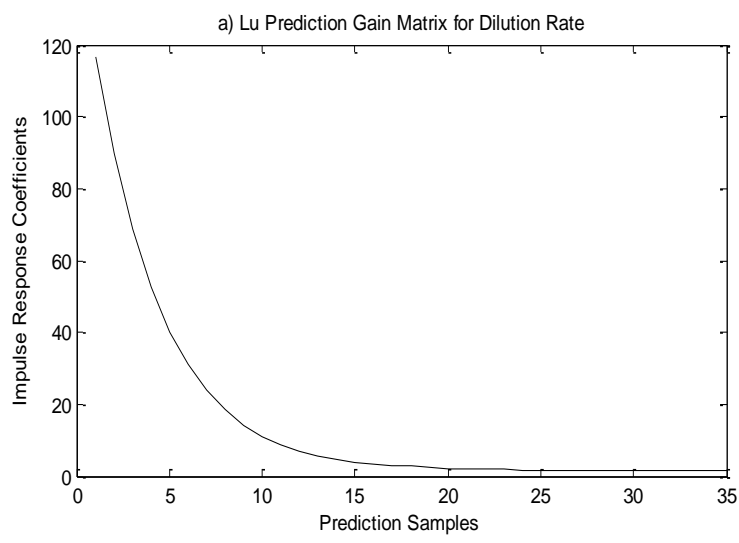

(a)

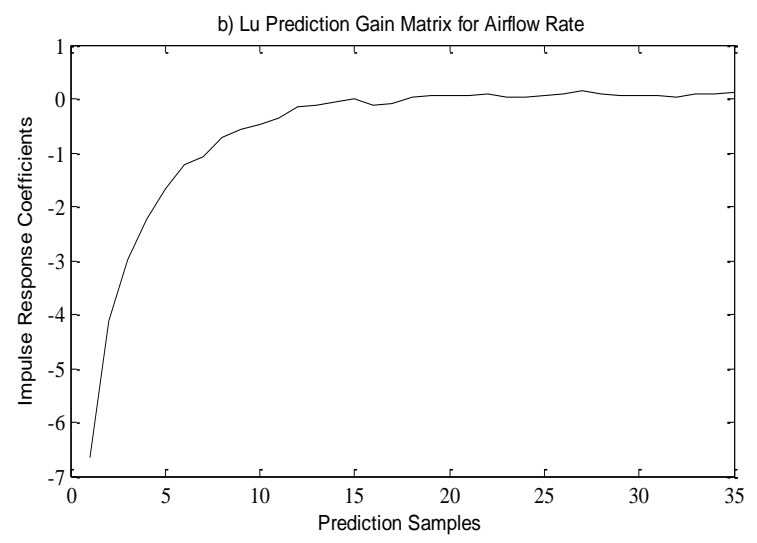

(b)

Figure 2. The values of $\mathrm{L}_{\mathrm{u}}$ for prediction gain coefficients of, (a) Future dilution rate, (b) Future airflow rate 


\subsection{Robustness tests for closed-loop DAMPC}

In order to access the closed-loop performance of the applied algorithm, a rigorous simulation analysis under different operating conditions and kinetic process parameters were considered and discussed in this section. The constant influent rates are considered while taking into accounted the kinetic model variations and different operation points. Two different performance criterions were calculated for each output (C: dissolved oxygen concentration, and $\mathrm{S}$ : substrate concentration) which is the integral square error (ISE) and the integral absolute error (IAE) for the purpose of assessment. In Table 4 listed the ISE and IAE of the ASP outputs under the applied DAMPC with two different cases of operating conditions:

- Case 1: The operating condition in this case is $S_{\text {in }}=200 \mathrm{mgl}^{-1}$ and $C_{\text {in }}=0.5 \mathrm{mgl}^{-1}$ with $\left[\begin{array}{llll}\mathrm{X} & \mathrm{S} & \mathrm{C} & \mathrm{X}_{\mathrm{r}}\end{array}\right]^{\mathrm{T}}=\left[\begin{array}{llll}215 & 55 & 6 & 400\end{array}\right]^{\mathrm{T}}$ and the varied kinetic parameters for the nonlinear term, $\mu_{\text {max }}, \mathrm{K}_{\mathrm{s}}$, and $\mathrm{K}_{\mathrm{c}}$.

- Case 2: The operating condition in this case is $\mathrm{S}_{\mathrm{in}}=200 \mathrm{mgl}^{-1}$ and $\mathrm{C}_{\mathrm{in}}=0.5 \mathrm{mgl}^{-1}$ with, $\left[\begin{array}{llll}\mathrm{X} & \mathrm{S} & \mathrm{C} & \mathrm{X}_{\mathrm{r}}\end{array}\right]^{\mathrm{T}}=\left[\begin{array}{llll}217.7896 & 41.2348 & 6.1146 & 435.5791\end{array}\right]^{\mathrm{T}}$ and the same varied kinetic parameters for the nonlinear term are also considered, $\mu_{\max }, \mathrm{K}_{\mathrm{s}}$, and $\mathrm{K}_{\mathrm{c}}$.

Results in Table 4 show the applicability of the controller algorithm to adapt both varied kinetic parameters and operating conditions. Therefore, system outputs will be regulated and the input reference trajectories will be tracked, irregardless of the conditions imposed on the real plant. Furthermore, no explicit model is formulated for the plant and any prior information about initial operating conditions is not needed, neither does the kinetic parameters.

Table 4. Performance test numerical values

\begin{tabular}{|c|c|c|c|c|c|c|c|c|c|c|c|}
\hline & \multirow{2}{*}{$\begin{array}{l}\text { Kinetic } \\
\text { parameters }\end{array}$} & \multicolumn{2}{|l|}{ ISE } & \multicolumn{3}{|l|}{ IAE } & \multirow{2}{*}{$\begin{array}{l}\text { Kinetic } \\
\text { parameters }\end{array}$} & \multicolumn{2}{|l|}{ ISE } & \multicolumn{2}{|l|}{ IAE } \\
\hline & & $\mathrm{S}$ & $\mathrm{C}$ & $\mathrm{S}$ & $\mathrm{C}$ & & & $\mathrm{S}$ & $\mathrm{C}$ & $\mathrm{S}$ & C \\
\hline \multirow[t]{3}{*}{ CASE 1} & $\begin{array}{l}\mu_{\max }=0.15 \\
\mathrm{~K}_{\mathrm{s}}=100 \mathrm{mgl}^{-1} \\
\mathrm{~K}_{\mathrm{c}}=2 \mathrm{mgl}^{-1}\end{array}$ & 132.7 & 1.133 & 107.9 & 16.74 & \multirow[t]{3}{*}{ CASE 2} & $\begin{array}{l}\mu_{\max }=0.15 \\
\mathrm{~K}_{\mathrm{s}}=100 \mathrm{mgl}^{-1} \\
\mathrm{~K}_{\mathrm{c}}=2 \mathrm{mgl}^{-1}\end{array}$ & 150.4 & 1.262 & 117.3 & 17.3 \\
\hline & $\begin{array}{l}\mu_{\max }=0.21 \\
\mathrm{~K}_{\mathrm{s}}=100 \mathrm{mgl}^{-1} \\
\mathrm{~K}_{\mathrm{c}}=3 \mathrm{mgl}^{-1}\end{array}$ & 680.1 & 18.64 & 332.8 & 59.93 & & $\begin{array}{l}\mu_{\max }=0.21 \\
\mathrm{~K}_{\mathrm{s}}=100 \mathrm{mgl}^{-1} \\
\mathrm{~K}_{\mathrm{c}}=3 \mathrm{mgl}^{-1}\end{array}$ & 462.2 & 13.57 & 246.2 & 46.2 \\
\hline & $\begin{array}{l}\mu_{\max }=0.21 \\
\mathrm{~K}_{\mathrm{s}}=150 \mathrm{mgl}^{-1} \\
\mathrm{~K}_{\mathrm{c}}=2 \mathrm{mgl}^{-1}\end{array}$ & 111.8 & 1.439 & 113.4 & 18.87 & & $\begin{array}{l}\mu_{\max }=0.21 \\
\mathrm{~K}_{\mathrm{s}}=150 \mathrm{mgl}^{-1} \\
\mathrm{~K}_{\mathrm{c}}=2 \mathrm{mgl}^{-1}\end{array}$ & 114.5 & 1.514 & 115.1 & 19.2 \\
\hline
\end{tabular}

\section{CONCLUSION}

In this paper, the design of the adaptive data-driven predictive controller for biological ASP is presented. The integration between the robustness and efficiency of subspace-based predictor estimation principal (where only geometrical tools are deployed without involving into nonlinear optimization); and the power of advanced unconstrained MPC design methodology (where MIMO systems can be controlled successfully) contributed to a robust-stable DAMPC for nonlinear ASP. From the control perspective, this work can be seen as an important investigation in the field 'model-free' control design since it has shown that the methodology can cope with the same issues of the 'model-based' control methods. This includes the ease tuning of MPC parameters particularly for multivariable systems. Although, only unconstrained case is considered in this paper, we anticipate that the robustness of the constrained case is naturally achieved. In conclusion, the results obtained from the implementation of the presented control methodology on nonlinear ASP, was encouraging, and it is proposed that these algorithms show much promise for further development and analysis in terms of storage requirements, calculation time, and analytical stability proofs to gain wide acceptance in industrial scale applications.

\section{ACKNOWLEDGEMENTS}

The authors would like to thank the Ministry of Education (MOE) PRGS vote R.J130000.7851.4L702 and the Universiti Teknologi Malaysia UTMHIR vote 08G74 for their financial and facility support of this work.

\section{REFERENCES}

[1] H-G. Han and J-F. Qiao, "Prediction of activated sludge bulking based on a self-organizing RBF neural network," J. of Process Control, vol. 22, no. 6, pp. 1103-1112, 2012.

[2] S. Huang, L. Zhang, H. Guo, P. Chen, W. Xia, and C. Hu, "Modeling and optimization of the activated sludge process," 2019 Chinese Control Conference (CCC), pp. 6481-6486, 2019. 
[3] V. Benito, J. Etxebarria, F. Goñi-de-Cerio, I. Gonzalez, P. Brettes, and A. Urkiaga, "Better understanding of the activated sludge process combining fluorescence-based methods and flow cytometry: A case study," $J$. of Environ. Sci., vol. 90, pp. 51-58, 2020.

[4] M. Fliess and C. Join, "Model-free control," Int. J. of Control, vol. 86, no. 12, pp. 2228-2252, 2013.

[5] E. Madadi, Y. Dong, and D. Söffker, "Comparison of different model-free control methods concerning real-time benchmark," J.of Dynamic System, Measurement and Control, vol. 140, no. 12, pp. 121014 1-9, 2018.

[6] Z. Hou and S. Xiong, "On model-free adaptive control and its stability analysis," IEEE Trans. on Automat. Contr., vol. 64, no. 11, pp. 4555-4569, 2019.

[7] H. Korving, A. de Niet, P. Koenders, and R. Neef, "Model based control at WWTP westpoort," Risk and Decision Analysis in Maintenance Optimization and Flood Management, Delf University Press, pp. 113-122, 2009.

[8] F. Smarra, A. Jain, T. de Rubeis, D. Ambrosini, A. D'Innocenzo, and R. Mangharam, "Data-driven model predictive control using random forests for building energy optimization and climate control," Appl. Energy, vol. 226, pp. 1252-1272, 2018.

[9] C. M. Chew, M. K. Aroua, M. A. Hussain, W. M. Zamri, and W. Ismail, "Evaluation of ultrafiltration and conventional water treatment systems for sustainable development: An industrial scale case study," J. Cleaner Production, vol. 112, no. 4, pp. 3152-3163, 2016.

[10] H. J. van Waarde, J. Eising, H. L. Trentelman, and M. K. Camlibel, "Data informativity: a new perspective on datadriven analysis and control," IEEE Transactions on Automatic Control, pp. 1-16, 2020.

[11] A. Barwal, "Influence of Mathematical - kinetic models for the removal of organics and nutrients from municipal wastewater in moving bed biofilm reactor," Int. J. Sci. Res. Multidiscip. Stud., vol. 5, no. 8, pp. 66-76, 2019.

[12] T. T. Lee, F. Y. Wang, and R. B. Newell, "Advances in distributed parameter approach to the dynamics and control of activated sludge processes for wastewater treatment," Water Res., vol. 40, no. 5, pp. 853-869, 2006.

[13] A. Iratni and N-B. Chang, "Advances in control technologies for wastewater treatment processes: Status, challenges, and perspectives," IEEE/CAA J. of Automatica Sinica, vol. 6, no. 2, pp. 337-363, 2019.

[14] D-J. Choi and H. Park, "A hybrid artificial neural network as a software sensor for optimal control of a wastewater treatment process," Water Research, vol. 35, no. 16, pp. 3959-3967, 2001.

[15] E. Petre, D. Selişteanu, C. Şulea-Iorgulescu, and S. Mehedinţeanu, "Mathematical modelling and control for an activated sludge process in a wastewater treatment plant," 2019 20th International Carpathian Control Conference (ICCC), pp. 1-6, 2019.

[16] N. A. Wahab, R. Katebi, J. Balderud, and M. F. Rahmat, "Data-driven adaptive model-based predictive control with application in wastewater systems," IET Control Theory \& Applications, vol. 5, no. 6, pp. 803-812, 2011.

[17] C. Vlad, M. I. Sbarciog, M. Barbu, and A. V. Wouwer, "Indirect control of substrate concentration for a wastewater treatment process by dissolved oxygen tracking," J. of Cont. Eng. and Appl. Infor., vol. 14, no. 1, pp. 37-47, 2012.

[18] K. J. Astrom and Bj. Wittenmark, "Adaptive control, ” Addison-Wesley Longman Publishing Co., Inc., 1995.

[19] S. Caraman, M. Sbarciog, and M. Barbu, "Predictive control of a wastewater treatment process," Int. J. of Comput. Commun. \& Control, vol. 2, no. 2, pp. 132-142, 2007.

[20] W. Favoreel, B. De Moor, and M. Gevers, "SPC: Subspace predictive control," 14th IFAC World Congr., Beijing, China, vol. 32, no. 2, pp. 4004-4009, 1999.

[21] P. Van Overschee and B. L. R. De Moor, "Subspace identification for linear systems: Theory-implementationapplications," Kluwer Academic Publishers Group, 1996.

[22] Z-S. Hou and Z. Wang, "From model-based control to data-driven control: Survey, classification and perspective," Informatin Science, vol. 235, pp. 3-35, 2013.

[23] R. Kadali, B. Huang, and A. Rossiter, "A data driven approach to predictive controller design," Control Eng. Pract., vol. 11, no. 3, pp. 261-278, 2003.

[24] X. Luo and Y. Song, "Adaptive predictive control: A data-driven closed-loop subspace identification approach," Abstract and Applied Anaysis, pp. 1-11, 2014.

[25] T. Hale and S. J. Qin, "Subspace model predictive control and a case study," Proceedings of the 2002 American Control Conference (IEEE Cat. No.CH37301), vol. 6, pp. 4758-4763, 2002.

[26] Y. Lv and R. Chi, "Data-driven adaptive iterative learning predictive control," 2017 IEEE 6th Data Driven Control and Learning Systems Conference, Chongqing, China, pp. 374-377, 2017.

[27] F. Nejjari, B. Dahhou, A. Benhammou, and G. Roux, "Non-linear multivariable adaptive control of an activated sludge wastewater treatment process," Int. J. of Adaptive Control and Signal Processing, vol. 13, no. 5, pp. 347-365, 1999. 